ESTUDOS RBEP

\title{
Por um olhar democrático às ações afirmativas*
}

Luis Otávio Vincenzi Agostinho

Vladimir Brega Filho

\section{Resumo}

Discute as ações afirmativas como um meio de que o Estado dispõe para atenuar as desigualdades e os privilégios de alguns indivíduos em relação a outros, como os afrodescendentes. As ações afirmativas se apresentam como instrumentos de estabilização, ainda que provisórios, garantindo a inclusão da parcela vulnerável. Analisa as estatísticas que atribuem ao cidadão negro os piores índices de salário, saúde, educação e saneamento básico, entre outros, quando comparado ao cidadão branco, e indica as medidas a serem tomadas pelo Estado para promover a cidadania dos que dela carecem. Conclui que não se trata de alocar, sem critérios e por um sentimento leigo de justiça, os negros em setores ocupados por brancos, mas de utilizar critérios legítimos de ingresso, com o fito de diminuir as desigualdades e promover uma concepção plural e radical de democracia.

Palavras-chave: ações afirmativas; igualdade racial; emancipação;

* Trabalho publicado nos Anais do XIX Encontro Nacional do (Conpedi - Conselho Nacional de Pesquisa e Pós-Graduação em Direito), realizado em Fortaleza no período de 9 a 12 de junho de 2010 . 


\section{Abstract \\ For a democratic look towards affirmative actions}

The present article discusses the affirmative policies as a way to reduce the inequalities and the privileges of some individuals in relation to others, as for example the black citizens. The affirmative actions are shown as a stabilizing instrument by guaranteeing the inclusion of the vulnerable people even if it is temporary sometimes. The study analyzes the data that attributes the worst indexes of health, education, wealth and basic sanitation to the black citizens in comparison to the white ones. Moreover, the analysis indicates some possible ways to promote citizenship through State initiative. It concludes that it is not only a question of reallocate black people to places usually occupied by white people but also the necessity to create a legitimate access criterion in order to promote a plural and radical democracy concept.

Keywords: affirmative actions; racial equality; emancipation; cordial racism

\section{Introdução}

Efetivar a igualdade material é tarefa que suscita muitas divergências e dificuldades. Em uma sociedade plural, como é o caso do Brasil, as ações afirmativas são medidas que buscam a efetivação deste preceito constitucional. Analisar juridicamente políticas públicas de inclusão imediata, contrárias ao conservadorismo histórico vivido em nosso País, é quebrar paradigmas e reconhecer minorias em sentido qualitativo como participantes ativas do processo democrático nacional.

A questão jurídica que envolve a inclusão de afrodescendentes nos diversos setores da sociedade por meio das ações afirmativas transformou-se em discussões que, muitas vezes, fogem do verdadeiro sentido do objetivo de tais políticas.

As cotas para negros, exemplo clássico de ações afirmativas (mas não o único), já são uma realidade em nosso cotidiano e surtem efeitos em nosso ordenamento jurídico há alguns anos, de forma a tornar-se secundária a discussão da necessidade ou não de existirem cotas em outros setores da sociedade. Elas existem e criam relações entre o Estado e particulares ou até mesmo entre particulares somente.

Dessa forma, hodiernamente, o obstáculo maior ao discurso e à implementação prática das ações afirmativas é a sua inclusão e conjugação com as políticas públicas instituídas pelo Estado. Em outras palavras, tem-se que criar um sistema visando à inclusão social mediante mecanismos 
previstos em normas jurídicas, evitando que tais medidas possam gerar na sociedade a impressão de que se trata de auxílio a minorias, desigualdade declarada, preferência e racismo cordial.

Operacionalizar as ações afirmativas supõe, primeiramente, esclarecimento a todos os cidadãos dos motivos pelos quais o órgão estatal foi levado a implantar políticas públicas direcionadas a certas minorias, em sentido qualitativo. Buscar a ratio juris das ações afirmativas, isto é, a razão do direito de se incluir, resume-se em uma tarefa de analisar os motivos pelos quais devem existir discriminações positivas em nome do princípio da igualdade, e não contrário a ele, como muito se tenta fazer crer.

Este trabalho analisa as divergências no tocante à inclusão dos afrodescendentes por meio das ações afirmativas como tentativa de efetivação da igualdade substancial entre os cidadãos do Brasil. Em virtude de o tema poder ser discutido sob diversas ópticas, propõe-se a análise filosófica das desigualdades a partir da matriz da democracia radical, proposta por Mouffe como forma de promover uma reflexão social de comprometimento e infinita responsabilidade para com o outro. Ainda, pretende-se discutir se esse ideal de justiça estaria mais próximo da realidade da parcela afrodescendente, a partir da adoção das ações afirmativas como instrumentos provisórios, mas que visem à sua emancipação.

\section{As implicações negativas da igualdade universal}

A universalidade e a transcendentalidade são características essenciais aos direitos humanos, responsáveis por impulsionar sua aplicação a todos os indivíduos, protegendo acima de tudo sua dignidade.

Os tratados internacionais de proteção a direitos humanos contribuem essencialmente por meio da universalidade normativa para difusão desses direitos, vinculando consequentemente os países signatários a cumprirem as diretrizes por eles enunciadas.

Em que pese a existência de tais instrumentos internacionais, nos quais os países signatários garantiriam o cumprimento de suas normas, as disposições, em sua maioria universais, representam certo perigo para a proteção de minorias, mesmo que tal assertiva possa parecer um paradoxo.

Obviamente necessárias são as diretrizes normativas sobre o tema, internacionais ou nacionais, sobretudo por advogarem à causa humanística da igualdade, rechaçando condutas intolerantes para com as minorias: religiosas, étnico-raciais ou de ordem sexual, entre outras.

Os direitos humanos demandam universalidade no sentido de propor e dar o primeiro passo na busca de uma mudança social, ao menos jurídico-formal. Entretanto, universalizar a igualdade mediante variados instrumentos jurídicos e acreditar na suficiência dessa teorização pode acabar sendo um engano, isso pelo fato de que se corre o risco de omissão estatal na criação de medidas pragmáticas que ponham em prática a construção literal bem organizada dos instrumentos jurídicos. 
A partir dessa concepção, Mouffe (1996, p. 26), na defesa de sua matriz de democracia plural e radical, salienta que a universalidade normativa seria a característica que mais excluiria certos grupos que teriam nesses instrumentos a efetivação da igualdade substancial e o idealismo de concretização democrática. Nesse sentido, afirma o seguinte paradoxo:

\begin{abstract}
Deve então salientar-se que esta nova fase da revolução democrática, embora sendo, à sua maneira, um resultado do universalismo democrático do iluminismo, também põe em causa algumas das suas apropriações. De facto, muitas destas lutas renunciam a qualquer aspiração de universalidade. Demonstram como em todas as afirmações de universalidade se esconde uma negação do particular e uma recusa de especificidade.
\end{abstract}

A universalização da igualdade é perigosa, pois pode deixar de provocar atos estatais para a implementação de medidas de inclusão social, uma vez que se insurgiria a falsa ideia da igualdade formal na análise de prescrições legais universais, por exemplo, no art. $1^{\circ}$ da Declaração Universal dos Direitos Humanos. ${ }^{1}$ Em seus ensaios, Mouffe (1996, p. 26) afirma veementemente serem os chamados ideais universalistas verdadeiros "mecanismos de exclusão".

Assim, segundo Mouffe, poderia haver uma limitação à concretização da igualdade material, interpretação que opera em desencontro com a real intenção de um tratado internacional. Poder-se-ia argumentar que não haveria outra forma de garantir direitos de igualdade, senão normatizá-los por meio de tais instrumentos. No entanto, tendo em vista esta recusa à especificidade, não se criariam mais atos eficazes visando à promoção da igualdade material entre a pluralidade de cidadãos. Gerar-se-ia, portanto, uma falsa ideia de igualdade, amparada por instrumentos internacionais de ampla publicidade entre seus signatários, todavia correndo o risco de serem ineficazes.

Diante da crítica apresentada pela matriz filosófica da democracia radical, sua proposta para mudança paradigmática dos ideais iluministas normativos preleciona:

Os novos direitos que hoje são reclamados são expressão de diferenças cuja importância só agora começa a ser afirmada e deixaram de ser direitos que possam ser universalizados. A democracia radical exige que reconheçamos a diferença - o particular, o múltiplo, o heterogéneo -, tudo o que, na realidade, tenha sido excluído pelo conceito abstracto de homem. O universalismo não é rejeitado, mas particularizado; o que é necessário é um novo tipo de articulação entre o universal e o particular. (Mouffe, 1996, p. 27).

A articulação apresentada acima, no sentido de se reconhecer a diferença e estabelecer uma democracia plural, parece bem demonstrada em propostas diversas de ações afirmativas, como na Lei $\mathrm{n}^{\circ}$ 11.340/2006 (Lei Maria da Penha), na Lei no 10.741/2003 (Estatuto do Idoso) e no art. 37, inciso VIII, da Constituição Federal ao dispor sobre percentual de cargos e empregos públicos para portadores de

\footnotetext{
1 "Todas as pessoas nascem livres e iguais em dignidade e direitos. São dotadas de razão e consciência e devem agir em relação umas às outras com espírito de fraternidade."
} 
deficiência, ainda que de eficácia limitada. Essa articulação é também vislumbrada em decisões administrativas, por exemplo, na desobrigação de atividade em confronto com a garantia da liberdade de culto de fiel da Igreja Adventista do Sétimo Dia, praticante da guarda sabática (do pôr-do-sol de sexta-feira ao pôr-do-sol de sábado), entre outras ações afirmativas que visem tratamento especial a determinada minoria a fim de garantir a isonomia.

No tema central deste trabalho, as ações afirmativas para igualdade racial necessitam de instrumentos pragmáticos especializados para a efetiva inclusão do afrodescendente nos setores da sociedade em que se verifica déficit de sua representatividade, medida democrática que inicialmente discrimina com o fito de, posteriormente, igualar seus destinatários com os demais cidadãos.

\section{Racismo cordial}

Após a criação da ideia de democracia racial, que afirmava a inexistência de racismo nas relações entre negros e brancos, sendo sustentada principalmente pelo sociólogo Gilberto Freyre na publicação da obra Casa Grande \& Senzala em 1933, vários foram os contrapontos que divergiram dessa concepção, afirmando seu desencontro com a realidade (2001, passim).

Assim, os embates na discussão da existência de preconceito racial e promoção pessoal em virtude da raça se tornaram cada vez mais frequentes. Nesse propósito, analisam-se as ponderações de Florestan Fernandes (1989, p. 11) acerca da necessidade de encarar a democracia racial com um viés crítico, pautando-se na análise do cotidiano do negro na sociedade:

\footnotetext{
Os fatos - e não as hipóteses - confirmam que o mito da democracia racial continua a retardar as mudanças estruturais. As elites, que se apegaram a ele numa fase confusa, incerta e complexa de transição do escravismo para o trabalho livre, continuam a usá-lo como expediente para "tapar o sol com a peneira" e de autocomplacência valorativa. Pois consideremos: o mito - e não os fatos - permite ignorar a enormidade da preservação de desigualdades tão extremas e desumanas como são as desigualdades raciais no Brasil; dissimula que as vantagens relativas "sobem" - nunca "descem" - na pirâmide racial; e confunde as percepções e as explicações - mesmo as que se têm como "críticas", mas não vão ao fundo das coisas - das realidades cotidianas.
}

Como aludido pelo historiador no final do século 20 e bem demonstrado na expressão "tapar o sol com a peneira", não havia enfrentamento à questão da desigualdade entre negros e brancos. Passou-se a considerar a igualdade formal como fator preponderantemente isonômico, de forma a se criar uma espécie de cordialidade no tratamento racial.

Dando prosseguimento à comparação histórica, apresenta-se como pensamento atual o estudo de Gomes (2003, p. 15), ao tratar da igualdade racial com a mesma essência com que fora tratada anteriormente: 
O tema é de transcendental importância para o Brasil e para o direito brasileiro, por dois motivos. Primeiro, por ter incidência direta sobre aquele que é seguramente o mais grave de todos os nossos problemas sociais (o qual, curiosamente, todos fingimos ignorar), o que está na raiz das nossas mazelas, do nosso gritante e envergonhador quadro social ou seja, os diversos mecanismos pelos quais, ao longo da nossa história, a sociedade brasileira logrou proceder, através das mais variadas formas de discriminação, à exclusão e ao alijamento dos negros do processo produtivo consequente e da vida social digna. Em segundo lugar, por abordar um tema nobre de direito constitucional comparado e de direito internacional, mas que é, curiosamente, negligenciado pelas letras jurídicas nacionais, especialmente no âmbito do Direito Constitucional.

Como exposto acima, a importância em se discutir o tema está na indiferença com que é tratado e na aceitação do status quo, admitindo-se implicitamente que a igualdade formal, disposta na Constituição (Brasil, 1988), é suficiente para garantir a superação das dificuldades de todos os que se encontrassem alijados do sistema, independentemente de suas raças.

Em nome da isonomia ou igualdade meramente formal dos concorrentes perante a lei, faz-se de conta que todos - ricos e pobres, fortes e fracos, sujeitos ou não ao preconceito de inferioridade - podem participar, numa postulada igualdade absoluta de condição social, da grande competição da vida, na qual deve ser premiado o concorrente mais capaz. (Comparato, 2006, p. 571).

Observa-se, portanto, que o enfrentamento do tema sempre encontrou barreiras sociais. Uma delas, sem dúvida, é a cordialidade com que é tratada a questão, de forma a não considerar um fenômeno que se evidencia tão presente na sociedade brasileira tal como o racismo.

A ideia de racismo cordial é uma construção feita a partir da observação da teoria elaborada por Holanda (1995, p. 107), ao conceituar o "homem cordial", personagem nitidamente encontrado em nossa sociedade:

Nenhum povo está mais distante dessa noção ritualista da vida do que o brasileiro. Nossa forma ordinária de convívio social é, no fundo, justamente o contrário da polidez. Ela pode iludir na aparência - e isso se explica pelo fato de a atitude polida consistir precisamente em uma espécie de mímica deliberada de manifestações que são espontâneas no "homem cordial": é a forma natural e viva que se converteu em fórmula. Além disso, a polidez é, de algum modo, organização de defesa ante a sociedade. Detém-se na parte exterior, epidérmica do indivíduo, podendo mesmo servir, quando necessário, de peça de resistência. Equivale a um disfarce que permitirá a cada qual preservar intactas sua sensibilidade e suas emoções.

Ainda que a afirmação não trate especificamente da cordialidade social no tratamento racial, há de se levar em conta a existência da dissimulação com que a questão é tratada pelo homem cordial moderno, a começar pela dificuldade existente em se debater o tema e reconhecer a prática de diversas restrições cotidianas, ainda que tênues, por motivo meramente racial. 
O sociólogo Alberto Carlos Almeida, em investigações realizadas pela Pesquisa Social Brasileira (Pesb), salienta que o Brasil vem assumindo ser um país racista. Por meio de questionamentos, trazendo percepções dos entrevistados pela análise de várias fotos de homens de diferentes raças, conclui que:

Nos atributos pobreza e malandragem, a diferença entre pardos e pretos é insignificante. Os pretos são considerados os que têm menos oportunidades na vida, e os pardos, os que mais se parecem com um criminoso. Particularmente nesse quesito, o resultado é revelador: o número de brasileiros que acham que os pardos são os que mais se parecem com um criminoso é três vezes maior do que o número dos que acham isso dos brancos. (Almeida, 2007, p. 230).

Almeida (2007, p. 257) traz ainda os resultados de uma pesquisa realizada com o seguinte questionamento: "Se você tivesse uma filha, preferiria que ela se casasse com um branco, um preto ou um pardo? Mesmo que o branco fosse mecânico de carro?". O intuito de tal intervenção foi mensurar o preconceito racial mediante a combinação de três raças (preto, pardo e branco) com três profissões (mecânico de carros, professor de ensino médio e advogado). Entre várias conclusões, há uma que merece destaque:

[...] resultado que merece atenção é a preferência dos brancos por outro branco para o casamento, ainda que com menor status social do que pardos ou pretos. Em todas as situações, mais da metade - 53\% para o branco mecânico [...], 57\% para o branco professor [...] e 63\% para o branco advogado [...] -, essa preferência se confirmou. O que mostra que, nesse sentido, os brancos são menos propensos à mistura com pardos ou pretos. Em segundo lugar estão os pretos e, por último, os pardos. De fato, são os pardos os que mais aceitam se misturar, de preferência com pessoas brancas.

Em que pesem os diferentes enfoques acerca do tema e a comprovação de que existe racismo na sociedade brasileira, há uma corrente que merece ser investigada. Ela argumenta basicamente que não há como se instituírem ações afirmativas para afrodescendentes no Brasil do mesmo modo como foram estabelecidas nos Estados Unidos.

Um dos grandes exemplos é o pensamento do antropólogo Antonio Risério, ao basear sua fundamentação no sentido de que o modelo de cotas para negros é uma cópia da divisão social estadunidense, que considera somente o indivíduo como "branco" ou "preto". Para o autor, a aplicação dessa fórmula não se amolda às particularidades do Brasil. Contudo, ele não nega a existência do racismo, pautando seu discurso na incompatibilidade do modelo norte-americano no cotidiano brasileiro.

O racismo brasileiro, por sua vez, é assunto que apresenta alguma complexidade. Ao contrário do que se vê na história política, jurídica e social dos EUA, o preconceito racial, no Brasil, nunca expressou nos termos de uma segregação explícita ou legalmente constituída. Nunca foi racismo institucionalizado. Nem tivemos, jamais, algo de equivalente à Ku Klux Klan, com seus incêndios, assassinatos e 
linchamentos. A realidade, aqui, é outra. [...] Porque tanto temos a aproximação generosa e o convívio entre as raças, como o preconceito, muitas vezes velado e envergonhado, mas nem por isso menos canalha e cruel. A existência deste racismo, porém, é incontestável. (Risério, 2007, p. 13).

O autor, portanto, inicia dividindo o modelo racista estadunidense das relações raciais brasileiras. Passa, após, a fundamentar sua contrariedade ao sistema de cotas raciais:

Lideranças negromestiças brasileiras resolveram então (ou foram levadas a) acreditar que, na importação do modelo dicotômico estadunidense, estaria a solução para o problema da arregimentação política de nossos mestiços de pele menos clara. Decidiram fechar os olhos para a cor - e pensar em termos de raça. Adotaram o pattern binário, converteram-se ao "racialismo", negaram parte de sua ancestralidade (a branca, obviamente) e surgiram assim, no campo social e político do país, como uma espécie de nova categoria étnica os neonegros. (Risério, 2007, p. 19).

Para o antropólogo, a adoção do modelo norte-americano de ações afirmativas para afrodescendentes desprestigia as relações de mestiçagem. Assim, em sua abordagem, o Brasil estaria negando que há uma raça em combinação com a branca e a negra, que sofreria discriminação na adoção de medidas afirmativas para inclusão do afrodescendente.

Ora, apesar de muito clara e concisa, a ideia do autor denota radicalidade. A importação do modelo norte-americano de ações afirmativas para afrodescendentes considera a influência negra na raça parda e não discrimina o percentual branco de sua existência. Numa discussão envolvendo a necessidade de emancipação do negro (preto ou pardo), que sofre diversas discriminações, ainda que cordiais e mascaradas, há de se salvaguardar a parcela negra de todos aqueles que a possuem. Independentemente da crença de que o mestiço é menos negro do que aqueles de descendência integralmente negra, tem-se que o afrodescendente é vulnerável socialmente, estando sempre em situação desprivilegiada.

Ao que parece, analisando o propósito de importar o modelo norte-americano para a realidade brasileira, vislumbram-se, tão somente, fatores que poderão contribuir para uma nova realidade social e contra a manutenção do status quo racializado. O prejulgamento e os preconceitos arraigados em relação a esse grupo vulnerável são repensados como uma forma de fortalecimento do ideal democrático e do princípio da igualdade.

O racismo cordial pode ser analisado também sob duas realidades: o instituto da adoção de crianças negras e o fenômeno do covering em relação aos negros.

\section{$O$ instituto da adoção e seus índices raciais}

Atualmente, o sistema de adoção opera em uma plataforma nacional, conhecida por Cadastro Nacional de Adoção (CNA), instituído por lei. É 
exemplo de um dos contrastes quando se fala na aceitação do negro no Brasil. Além disso, muito bem exprime a cordialidade com que o racismo é tratado em nossa sociedade:

No entanto, um dos grandes entraves para o aumento do número de adoções é justamente o perfil que as pessoas cadastradas traçam para os futuros filhos adotivos. Segundo a juíza Cristiana Cordeiro, membro do comitê gestor do CNA, a maioria deseja uma criança sem problemas de saúde, de cor branca, do sexo feminino e recém-nascida. (Jornal do Senado, 2009).

Fator interessante que se demonstra e que poderia esclarecer a preferência por crianças brancas é o fato de que a maioria dos casais aptos a adotarem uma criança ou adolescente se autointitula branca:

Os dados, obtidos pelo Estado, mostram que até ontem havia no País 11.404 pretendentes a adotar uma criança. E escancaram uma equação difícil de fechar: 80,7\% deles querem crianças de até 3 anos. Mas, das 1.624 crianças inscritas no cadastro, apenas 66 têm até essa idade. Ou seja, menos de 5\%. A grande parte é formada praticamente de adolescentes: 795, quase a metade do total, está entre 12 e 17 anos. Além disso, 66,5\% dos pretendentes não querem crianças negras. Preferem brancas ou pardas. Dos que querem adotar, 70\% se declaram brancos. (Duailibi; Iwasso, 2008, p. 17, grifo nosso).

Embora possa parecer normal que uma família de cor branca prefira uma criança branca, por questões de semelhança, o índice é preocupante. O alto índice de rejeição a crianças negras pode ser analisado como uma das exteriorizações do "racismo cordial" de nossa sociedade.

Conforme noticiado pela Agência Câmara de Notícias em 26 de maio de 2008, há no Brasil 80 mil orfanatos e 120 mil crianças que vivem em abrigos e orfanatos. De acordo com a Associação dos Magistrados Brasileiros (AMB), cerca de 7 mil casais brasileiros e 300 estrangeiros esperam na fila de adoção.

Pela mesma pesquisa, ainda há o percentual de que, dos 15\% dos brasileiros dispostos a adotar, 32,1\% escolheriam crianças de até 6 meses e 28,2\%, de 6 meses a 3 anos. Estudo realizado pelo Instituto de Pesquisa Econômica Aplicada (Ipea) ${ }^{2}$ indica que a maioria das crianças nos abrigos é de meninos (58,5\%), afrodescendentes (63,6\%), na faixa entre 7 e 15 anos de idade $(61,3 \%)$.

Talvez o exemplo da adoção de crianças negras seja o mais inquietante a demonstrar que a sociedade possui o preconceito declarado, ao verificar tais estatísticas.

\section{O fenômeno do covering}

${ }^{2}$ Agência Câmara de Notícias, 2008, on-line.

De fundamental importância no debate é a comparação da realidade brasileira com o fenômeno chamado covering, proposto por Kenji Yoshino, professor da Yale Law School, em que apresenta a tese 
de que grupos excluídos da sociedade, como negros e homossexuais, de alguma forma somente seriam por ela aceitos se tivessem amenizadas algumas de suas características particulares, justamente as que os levam a ser diferentes, como o uso de certo corte de cabelo no caso dos negros (cabelos crespos e dreads) ou a manifestação de afeto entre homossexuais, como o simples caminhar de mãos dadas em locais públicos.

\begin{abstract}
Rogers vs. American Airlines - decisão do ano de 1981, nunca anulada, demonstra esta dinâmica. Rogers era uma afro-americana, que trabalhou para a American Airlines como agente de operações aeroportuárias. Este trabalho foi alvo de uma política de aliciamento de trabalhadores impedidos de usar penteados trançados. Diante dela, a empresa foi categórica em proibir penteados referentes à raça. No entanto, a política entrou em conflito com as mulheres afro-americanas, com quem os tipos de penteado (tranças) estão fortemente associados. Rogers, que usava trancinhas, desafiou a política contra o Título VII, por discriminação de gênero e raça. O parecer do tribunal de comarca, que é a disposição final deste caso, foi favorável às alegações da companhia aérea em ambas as reivindicações. (Yoshino, 2006, p. 131, tradução livre).
\end{abstract}

Conforme exposto na análise comparativa do caso racial prático, o fenômeno covering pode ser encontrado na sociedade brasileira, imperceptivelmente, por meio de recomendações sutis feitas a empregados como condições para manutenção do emprego, aproximando-se cada vez mais do modelo padrão do homem branco, de origem europeia. Nesse sentido, aponta Rocha (1996, p. 284):

Do salário à internet, o mundo ocidental continua sendo o espaço do homem médio branco. Das prisões às favelas, o mundo ocidental continua marginalizando os que são fisicamente desiguais do modelo letrado e chamado civilizado pelos que assim o criaram. Sem oportunidades sociais, econômicas e políticas iguais, a competição pedra de toque da sociedade industrial capitalista - e, principalmente, a convivência são sempre realizadas em bases e com resultados desiguais.

Em outras palavras, há uma tentativa de mitigação das aparências exteriorizadas das minorias, abrandando suas particularidades, as próprias que as fazem minoria, na tentativa sempre frustrada de se aproximar do padrão social.

A manutenção do status quo visa à continuação na padronização do ser socialmente aceitável, exemplo de postura, caráter e atitudes. O outro acaba sendo alijado da convivência social, ainda mais se foge dos padrões impostos como forma de vida.

Exemplos como este são diversamente encontrados no Brasil diariamente, mas que, na maioria das vezes, acabam sendo imperceptíveis, dado o costume social com o mundo capitalista, demonstrando que se está acostumado em aceitar e difundir o padrão estabelecido e pensar que o que foge à regra está errado. Revela, sobretudo, falta de compromisso ético para com o outro. 


\title{
O sentido democrático das ações afirmativas
}

O argumento para a existência das ações afirmativas alude à necessidade de uma oportunidade igual a todos numa sociedade em que há tantas vítimas de preconceitos e discriminações. A aplicação de tais discriminações positivas serviria para amenizar esse contexto de exclusão social e promover emancipação daqueles que enfrentam diversos obstáculos para a plena igualdade com os demais (Atchabahian, 2006, p. 167).

Por meio de obrigações e incentivos criados pelo Estado, estipulam-se aos setores públicos e privados cotas de participação para cidadãos pertencentes a uma minoria, geralmente alvos de discriminação social, de modo que tais espaços sejam preenchidos de forma plural, proporcionalmente aos grupos existentes na sociedade.

Motiva-se a defesa de tais medidas o fato de que existem setores da sociedade, geralmente os mais concorridos, como vagas em universidades públicas e cargos de empresas, em que há certa seletividade nos processos, seja pela existência de pré-conceitos firmados, seja pela questão da falta de oportunidades saboreada por alguns, enfim, sempre se tratando de relações de diferença social.

Como salienta Rocha (1996, p. 287), considerando que o princípio da isonomia, em seu viés formalista, não é suficiente para garantir a verdadeira igualdade, deve o Estado assegurar mecanismos para que todos os grupos em condições de vulnerabilidade possam ser incluídos por intermédio de medidas diferenciadas.

\begin{abstract}
Não bastavam as letras formalizadoras das garantias prometidas; era imprescindível instrumentalizarem-se as promessas garantidas por uma atuação exigível do Estado e da sociedade. Na esteira desse pensamento, pois, é que a ação afirmativa emergiu como a face construtiva e construtora do novo conteúdo a ser buscado no princípio da igualdade jurídica. O Direito Constitucional, posto em aberto, mutante e mutável para se fazer permanentemente adequado às demandas sociais, não podia persistir no conceito estático de um direito de igualdade pronto [...]. Daí a necessidade de se pensar a igualdade jurídica como a igualação jurídica que se faz, constitucionalmente, no compasso da história, do instante presente e da perspectiva vislumbrada em dada sociedade: a igualdade posta em movimento, em processo de realização permanente; a igualdade provocada pelo Direito segundo um sentido próprio a ela atribuído pela sociedade.
\end{abstract}

Adequadas às demandas sociais, as ações afirmativas garantem a materialização do ideal democrático, em que o efeito negativo de discriminações históricas (verificados seus resquícios atualmente de forma clara) passa a ser combatido por meio de mecanismos de verdadeira inclusão emancipatória.

A ação afirmativa é, pois, a expressão democrática mais atualizada da igualdade jurídica promovida na e pela sociedade, segundo um comportamento positivo normativa ou administrativamente imposto ou permitido. Por ela, revela-se não apenas um marco equivocado da discriminação havida no passado em relação a determinados grupos 
sociais, mas, principalmente, uma transformação presente que marca um novo sinal de perspectivas futuras, firmadas sobre uma concepção nova, engajada e eficaz do princípio da igualdade jurídica. (Rocha, 1996, p. 295).

Analisando a ação afirmativa sob o viés da filosofia da diferença, inclina-se ao argumento de que tais medidas formam verdadeiro instrumento crítico à inércia da lei universal, pautando-se em mecanismos de inclusão imediata, em curto prazo, mas legitimados por uma condição especial, tal qual é a desigualdade jurídica. É o que propõe Kozicki (2003, p. 145), ao salientar que as relações de isonomia entre atores desiguais encontram respaldo no conceito de democracia:

Não a democracia liberal nos moldes em que ela é tradicionalmente concebida, mas em uma nova perspectiva de democracia, radical e plural, pois é somente na democracia que se pode conceber a não totalização; somente a democracia pode proporcionar um sentido de comunidade onde a diferença seja efetivamente constitutiva do social.

A articulação apresentada acima, no sentido de se reconhecer a diferença e afirmar a democracia radical, parece bem demonstrada em propostas diversas de ações afirmativas para igualdade racial, assim como em todas suas outras espécies (portadores de necessidades especiais, mulheres, homossexuais, etc.). A fim de ilustrar o caso dos afrodescendentes, citam-se como exemplos institutos infraconstitucionais, como a Lei no 10.639/2003 (Brasil, 2003) e o Projeto de Lei no 6.264/2005 (Brasil, 2005), que serão discriminados adiante.

Aplicando a teoria à prática, as ações afirmativas se apresentam como um caminho na busca da democracia radical, medidas compensatórias para inclusão, na espécie das ações afirmativas para igualdade racial. Como modelo idealizado de democracia, as medidas inclusivas são propósitos de um Estado interventor, que é chamado a se manifestar para a garantia da igualdade substancial perante as diferenças sociais. Mouffe (2004, p. 383) dá ensejo a movimentos sociais que busquem a efetiva inclusão:

De fato, nós devemos reconhecer que a democracia não exige uma teoria da verdade ou noções como incondicionalidade ou universalidade. O que se exige para a democracia é um conjunto de práticas e movimentos pragmáticos que objetivem convencer as pessoas a ampliar seu grau de comprometimento com os outros e construir uma sociedade mais inclusiva.

Assim, numa releitura de Kozicki (2003, p. 158) acerca da perspectiva radicalista apresentada por Mouffe, propõe-se uma nova forma de pensar o ideal democrático, em que o conflito e o antagonismo são condições essenciais para a busca da democracia.

A democracia radical pressupõe um contínuo caminhar em direção à democracia, no sentido de concebê-la como démocratie à-venir. A democracia possível é sempre uma democracia futura, tendo em vista que o momento de sua realização implicaria sua desintegração, uma vez que a mesma já não faria mais sentido. O conflito e o antagonismo, 
no dizer de Mouffe, são as condições de possibilidade e impossibilidade da realização da democracia.

Seguindo essa linha, diversos movimentos sociais engajados para a realização de uma igualdade material, atuando como partes do conflito social, demonstram suas vulnerabilidades e exigem do Estado medidas efetivas para sua inclusão. Assim, por meio de medidas pragmáticas, como é o caso das ações afirmativas, busca-se a aproximação na concretização da democracia plural.

\section{A força normativa e a infinita responsabilidade para com o outro}

Passa-se a analisar a efetividade que a norma de caráter inclusivo possui no campo social, como mecanismo de reflexão, promovendo o repensar do princípio da isonomia na defesa de uma minoria racial.

Diferentemente de uma classe que necessita de privilégios por uma questão de saúde, por exemplo, como é o caso dos idosos que têm prioridade nas filas de repartições púbicas e privadas, a proteção legal aos afrodescendentes demanda reflexões histórico-sociais e uma sedimentação do significado de democracia.

Como salientado anteriormente, o ideal democrático deve ser analisado sob a necessidade imediata de se eliminarem os abismos sociais existentes entre os cidadãos em virtude de pressupostos étnico-raciais.

Segundo Barroso (2002, p. 76), as normas jurídicas, quer se destinem a organizar o desempenho de alguma função estatal, quer tenham por finalidade disciplinar a conduta dos indivíduos, revestem-se sempre da característica que é própria ao direito: a imperatividade.

Tal imperatividade, por si só, não garante a real intenção de uma norma, que é sua efetividade. Assim sendo, passa-se a analisar a efetividade dos institutos jurídicos sob o prisma das ações afirmativas.

Cabe distinguir da eficácia jurídica o que muitos autores tratam como eficácia social da norma, que se refere, como assinala Reale (1973, p. 135), ao cumprimento efetivo do direito por parte de uma sociedade, ao reconhecimento do direito pela comunidade ou, mais especificamente, aos efeitos que uma regra suscita por meio de seu cumprimento. Em outras palavras, trata-se da concretização do comando normativo no cotidiano social.

A efetividade significa, portanto, a realização do Direito, o desempenho concreto de sua função social. Ela representa a materialização, no mundo dos fatos, dos preceitos legais e simboliza a aproximação, tão íntima quanto possível, entre o dever-ser normativo e o ser da realidade social. (Barroso, 2002, p. 85).

Assim, na hipótese de uma norma instituir determinada ação afirmativa, deve-se atentar para o caráter de discriminação lícita, pautado no dever de discriminar pelo Estado. 
Alexy (1999, p. 397) inicia o assunto com a seguinte máxima: "Se há uma razão suficiente para impor um tratamento desigual, então um tratamento desigual impõe-se." Trata-se de legitimar perante a sociedade o tratamento a ser imposto pelo Estado em prol de um grupo que se encontra em condições de vulnerabilidade ante os demais. O restante social, por sua vez, pressupõe a condição de responsável por esta diferenciação, uma vez que a sociedade forma um todo complexo e uno.

Ao se falar da diferenciação das minorias como um dos aspectos marcantes da contemporaneidade, insurge-se a hipótese proposta por Laclau (2007, p. 49, tradução livre):

Suponhamos que um grupo tenha algumas reivindicações - por exemplo, para oportunidades iguais em emprego e educação, ou até exigindo o direito de possuir escolas confessionais. Na medida em que essas reivindicações são apresentadas como direitos que eu compartilho como um membro da comunidade com outros grupos, supõem-se que eu não sou simplesmente diferente dos outros, mas, em alguns aspectos fundamentais, igual a eles.

Conforme salientado, a reivindicação por emancipação de grupos alijados da sociedade comprova a busca por uma igualdade material que se perfaz na ideia do compartilhamento entre os membros de uma comunidade, passando-se a uma consciência de isonomia entre todos. É a nítida ideia do reconhecimento da diferença. Materializa-se nessa concepção o próprio paradoxo da igualdade, haja vista que o dever de diferenciação é a própria igualdade analisada sob a óptica do grupo oprimido.

Justamente nesse ponto, as ações afirmativas se demonstram espécies de movimentos pragmáticos comprometidos com a inclusão social do outro, baseando-se na identificação dos sujeitos. A partir daí, infere-se a ideia do cidadão comprometido no espaço público, onde a cidadania e o reconhecimento do outro formam o centro das relações sociais (Kozicki, 2004, p. 344).

A ideia de infinita responsabilidade para com o outro, atribuída ao pensamento de Lévinas, é analisada como a coobrigação que os "mesmos" possuem em relação aos "outros", quando se verifica a assimetria nas relações sociais. Numa releitura de sua obra, Dussel (2000, p. 368) apresenta tal abordagem acerca das relações entre os sujeitos sociais pautadas na coobrigação.

A "vontade" para Lévinas não é nem deficiente nem arbitrária, nem tampouco egoísta e lançada a uma morte suicida. Quando o outro aparece em posição de assimetria (que enquanto vítima vem "de cima" e como "superior" eticamente: me obriga), a vontade fica antes de toda decisão impactada como "responsável" (como o que antes de tudo assume o outro).

Seguindo suas prerrogativas, Lévinas (apud Dussel, 2000, p. 370) atribui suas concepções éticas por meio de uma análise de verdadeiro compromisso entre os sujeitos sociais:

O rosto do próximo [que encontro na proximidade] significa para mim uma responsabilidade irrecusável, precedendo todo consentimento 
livre, todo pacto, todo contrato. Ele escapa a toda representação; ele é defecção mesma de toda fenomenalidade [...] O desvelamento do rosto é nudez - sem forma - abandono de si, envelhecimento, morrer; mais desnudo que a nudez: pobreza, pele desgarrada; pele desgarrada: pegadas do si-mesmo.

Como as concepções até agora referidas são estritamente éticas, o pensamento de Lévinas necessitaria de uma concretização no mundo político. Assim, conforme demonstra Kozicki (2003, p. 146), a passagem da concepção ética para a concepção política é marcada pela chegada de um terceiro componente, que se materializa na concepção de julgamento, sendo a própria questão da justiça.

A relação do eu com o outro é notadamente uma relação de assimetria, de radical desigualdade. A passagem da ética para a política é caracterizada pela chegada de um terceiro, uma relação com todos os outros. A relação com o outro é uma relação de proximidade - face a face (face to face), de responsabilidade que antecede qualquer questionamento. Tal chegada (do terceiro), justamente, marca a transição da ética para a política em Lévinas. Pois aqui é que surge a questão do julgamento, a própria questão da justiça.

A tese leviniana, anteriormente fundada na relação entre dois personagens (o mesmo e o outro), passa a ganhar noções de concretização fática com a chegada do julgamento, terceiro elemento responsável pela transição da ética para a política. Assim, verificar-se-á juridicamente a relação imposta anteriormente, de infinita responsabilidade para com o outro.

Em termos práticos, tais concepções referentes à força da lei e à ideia de responsabilidade para com o outro estão intrinsecamente presentes no conceito e na aplicação das ações afirmativas para igualdade racial.

Por meio de uma carga normativa de aplicabilidade imediata e inclusão social com vista à democracia pluralista, as ações afirmativas para inclusão do afrodescendente trazem à sociedade a responsabilização pela vulnerabilidade da parcela (condição legitimadora dessa conduta estatal), de forma a efetivar a cidadania e o combate à intolerância.

Assim, o ser da realidade social é pressionado pelo dever-ser normativo, passando a buscar a aproximação da democracia plena entre os desiguais, por ser questão de responsabilidade social para com o outro, sujeito distante numa realidade assimétrica, radicalmente desigual.

\section{Ações afirmativas como atos de estabilização}

Valendo-se da mesma linha de fundamentação empregada por Lévinas acerca do tratamento de justiça, passa-se a analisar os argumentos trazidos por Derrida na formulação de uma teoria à possibilidade de justiça e suas relações com o direito. No estudo de sua obra, Kozicki (2005, p. 130) afirma que, para o filósofo, não existe uma resposta certa para o direito no tocante à melhor forma de interpretação e aplicação da 
norma jurídica; a melhor forma de equacionar as relações entre o direito e a justiça é algo que sempre permanecerá em aberto.

[...] a análise da aplicação do direito se reveste da mesma dificuldade que caracteriza as sociedades democráticas: é necessário um tipo de interpretação jurídica que, reconhecendo a abertura e contingência dos conteúdos jurídicos, não se revista de um caráter totalizador ou definitivo, estando sempre aberta a novas possibilidades significativas. Porém, ao mesmo tempo, a interpretação e aplicação do direito pelos tribunais deve, necessariamente, representar padrões relativamente rígidos de conduta e ser o instrumental necessário, porém nem sempre suficiente, para a solução dos conflitos sociais. Nisto reside a dificuldade contida nessa problemática: ainda que não exista uma única resposta certa para a democracia e o direito, é necessário que se busquem respostas tanto no plano político quanto no plano jurídico e que estas respostas representem, ainda que provisoriamente, atos de estabilização. (Kozicki, 2005, p. 131).

Como salienta a autora, tais respostas, buscadas no mundo dos fatos, funcionariam como atos de estabilização, ainda que provisórias, desencadeando sua influência na sociedade, de forma a assegurar os direitos reivindicados por várias minorias, após se estabelecerem os conflitos.

Esta afirmação fundamenta integralmente as ações afirmativas, que pressupõem medidas emergenciais destinadas, muitas vezes, a relativizar os estigmas sociais e promover um "repensar" coletivo, além de serem verdadeiros instrumentos de estabilização.

Nessa perspectiva, a melhor ideia da busca de justiça seria dada pelo ideal de emancipação do outro, que jamais foi realizado e que nunca deve ser esquecido (Kozicki, 2003, p. 151). Portanto, a luta pela democracia (radical) é a forma política mais apta a configurar esta perspectiva de justiça (configurada como aporia, um não caminho).

Sobre a concepção de justiça, atrelada à utilização de instrumentos de estabilização, Derrida (2007, p. 30) aponta:

Aporia é um não-caminho. A justiça seria, deste ponto de vista, a experiência daquilo que não podemos experimentar [...] uma vontade, um desejo, uma exigência de justiça cuja estrutura, não fosse uma experiência da aporia, não teria nenhuma chance de ser o que ela é, a saber, apenas um apelo à justiça.

Nas democracias modernas, há uma pretensão quanto à implantação de um modelo funcional de justiça, motivo pelo qual se busca uma definição de seu conceito, como se assim fosse um instituto jurídico (que, mediante suas características, pudesse ser esculpido e ganhar forma sólida). No entanto, não há como definir justiça sem considerar que esta é sempre algo "por acontecer".

Assim, apesar de essa busca pelo conceito de justiça ser permanente, as ações afirmativas, como instrumentos provisórios de emancipação de minorias, contribuem consideravelmente para a responsabilização da sociedade para com o outro.

[...] se a justiça representa o encontro com o outro, a infinita responsabilidade que o outro demanda, a verdadeira experiência 
da alteridade, ela é algo que nunca se apresenta. Ainda assim, ela pode significar a possibilidade da transformação do direito e da política, enquanto percebida como uma responsabilidade inafastável e inadiável. [...] Nesse sentido, a democracia seria a forma política mais apta a significar esta perspectiva de justiça. Perspectiva esta que não se esgota na ação política, mas pressupõe a ação política. Não se contém nos limites do ordenamento jurídico, mas pressupõe o direito como elemento de estabilização e prioriza o momento da decisão, ou melhor, do julgamento (significado este por um compromisso ético). Essa democracia pode ser significada pela busca infinita da justiça e representada por um compromisso com o outro. Democracia que em si também é um por acontecer. A radicalização da democracia, compreendida pelo aprofundamento das relações democráticas; uma democracia plural, que possa reconhecer o outro em toda sua plenitude e que, indo além da razão, possa captar a importância das paixões como força motriz das ações humanas. (Kozicki, 2003, p.150-151).

Dessa forma, independentemente da carga teórica que se utiliza na tentativa de conceituação de justiça, deve-se sempre se ater à valorização da condição humana, haja vista que essa seria a própria essência da justiça.

Assim, nessa óptica humanista de busca por justiça, é necessária a análise da ideia de justiça em Walzer (2003, p. 1), que atribuiu à sociedade dos homens o caráter distributivo em todas as suas relações, em cujo horizonte se exercem tipos analógicos de justiça relativamente aos grupos dominantes e dominados. Isto traz a ideia de "igualdade complexa", em que:

Uma concepção mais ampla da justiça exige não que os cidadãos mandem e sejam por sua vez mandados, mas que mandem numa esfera e sejam mandados em outras - onde mandar não significa exercer poder mas desfrutar de uma porção maior do que outros indivíduos, seja qual for o bem distribuído. (Walzer, 2003, p. 252).

Numa releitura de sua obra por meio do pensamento ético-libertário de Dussel, estabelece-se que a dominação entre grupos nas relações do poder é inevitável. Entretanto, a partir de uma justiça distributiva, a dominação existiria de forma diversificada, ou seja, o grupo dominado em alguns setores poderia ser o dominante em outros, e a sociedade passaria a buscar uma forma assimétrica.

Mediante exemplos práticos suscitados no trabalho, analisa-se a emancipação dos afrodescendentes na conquista de postos de trabalho e funções dos quais não desfrutam atualmente com solidez, por exemplo, mais negros e pardos atuando como juízes, promotores e cargos de função social relevante aos olhos da sociedade e, também, como representantes políticos e chefes de secretarias executivas; enfim, uma maior distribuição dos cargos públicos e empregos privados, realidade contraposta ao que se costuma analisar na sociedade brasileira.

Ainda nessa hipótese de necessidade de se criarem mecanismos para os conflitos sociais, Walzer (2003, p. 430) afirma:

A justiça é relativa aos significados sociais. De fato, a relatividade da justiça provém da definição clássica não relativa de dar a cada pessoa o 
que lhe é devido. [...] Só podemos dizer o que é devido a esta ou àquela pessoa depois de saber como essas pessoas se relacionam entre si por intermédio do que fazem e distribuem. [...] Existe um número infinito de vidas possíveis, moldadas por um número infinito de possíveis culturas, religiões, acordos políticos, situações geográficas, etc. Determinada sociedade é justa se sua vida substantiva é vivida de determinada maneira - isto é, de maneira fiel às interpretações em comum dos membros. (Quando as pessoas discordam com relação ao significado dos bens sociais, quando as interpretações são polêmicas, então a justiça exige que a sociedade seja fiel às discordâncias, oferecendo canais institucionais para sua expressão, mecanismos de julgamento e distribuições alternativas).

Justamente onde Walzer abre os parêntesis para tratar da exceção da sociedade em que não há interpretação comum dos membros é onde pressupõe a necessidade de distribuições alternativas para se buscar a igualdade diante do pluralismo social.

A emancipação das classes, portanto, estaria assegurada de forma que os grupos excluídos, obtendo a parcela distributiva da justiça, estariam desfrutando de porções das quais não teriam privilégio na sociedade liberal burguesa.

Assim, embora muitas vezes a justiça seja encarada de forma diferenciada, sua essência pauta-se na efetiva necessidade de promoção da democracia, ainda que buscada por meio de medidas provisórias (atos de estabilização), por intensa fidelidade social à condição do outro, como é o caso das ações afirmativas para igualdade racial.

\section{Considerações finais}

A presença de ações afirmativas é um meio do qual o Estado dispõe para atenuar as desigualdades e os privilégios que algumas classes possuem em relação a outras, ainda que não declarados, mas intrínsecos no âmago social, como é o caso dos afrodescendentes.

Faz-se necessária a utilização de instrumentos concretos na busca da justiça política, saboreada minimamente como senso de justiça, haja vista seu caráter inatingível (aporia).

Nesse sentido, o ideal democrático é a melhor condução à experiência da justiça. Mediante uma abertura na interpretação constitucional que não se limita a um caráter definitivo (igualdade formal), as ações afirmativas apresentam-se como instrumentos de estabilização, que, ainda de caráter provisório, conseguem promover a emancipação da parcela afrodescendente excluída da sociedade.

Atente-se para o fato de que o caráter promotor de estabilização visa combater principalmente os paradigmas totalizadores da democracia liberal, como o exemplo do universalismo normativo e o da igualdade meramente formal.

Em defesa das ações afirmativas, encontram-se argumentos concretos para o combate à discriminação racial, que é difundida desde as práticas sociais mais simples, como o preconceito em relação a certo tipo de corte 
de cabelo que valorize a cultura africana, até o extremo oposto, na hipótese de grupos como os White Power, pregando o racismo declarado contra afrodescendentes, por exemplo. Dessa forma, esquece-se do argumento tão utilizado acerca da compensação histórica, passando a privilegiar a análise fenomenológica atual, e privilegia-se o argumento de luta pela emancipação da classe, contra os antigos preconceitos em razão dos fenótipos afrodescendentes e o abismo social vigente em comparação com os brancos.

Ora, considerando as diversas estatísticas que atribuem ao cidadão negro os piores índices em diversos setores sociais, tem-se a provocação necessária de medidas a serem tomadas pelo Estado, em seus diferentes órgãos, a fim de promover a igualdade material, de forma imediata, àqueles subjugados socialmente.

Numa democracia representativa em que não há igualdade de oportunidades, carregada por um olhar social racista ainda que cordial, as ações afirmativas constituem medidas emergenciais que devem ser implementadas nos diversos setores da sociedade (como cotas em universidades, empregos públicos e privados, políticas públicas de saúde, incentivo à educação inserida na cultura africana), onde se verifica déficit de representatividade afrodescendente, hipóteses bem salientadas no conteúdo original do Projeto de Lei n ${ }^{\circ}$ 6.264/2005 (Brasil, 2005), que visa instituir o Estatuto da Igualdade Racial. Ainda que tenha sofrido diversas modificações que retiraram de suas previsões mecanismos importantes para a emancipação da parcela, tem-se que políticas públicas nesse sentido, desde que implementadas seriamente, convergem à materialização da concepção democrática pluralista.

Não se trata da defesa da mera alocação, sem critérios, dos negros em setores geralmente ocupados por brancos, por um sentimento leigo de justiça. Trata-se da utilização de critérios legítimos de ingresso, pautados em estudos que demonstram a verdadeira face da nação brasileira, como é o caso do Relatório Anual das Desigualdades Raciais. Projeta-se o desenvolvimento da nação para a mudança social, menos racializada, menos cordial e apenas "tolerante" com o outro, o que não é suficiente.

Frise-se que, pela aplicação das ações afirmativas para igualdade racial, não se deve deixar de cobrar o próprio Estado para que invista na concretização dos direitos sociais à parcela, como educação, saúde e trabalho. O caráter de provisoriedade e estabilização de tais medidas não pode ser barreira à atuação do Estado. Elas possuem, sim, a função de promover o "repensar social" por meio da edição de leis e atos administrativos que conscientizem a todos. No entanto, a continuidade dos investimentos a longo prazo - principalmente em educação pública de qualidade, vetor potencialmente decisivo para uma realidade social mais igualitária - é de suma importância para a evolução do presente cenário.

$\mathrm{Na}$ busca desse ideal, salutar é a relação leviniana de infinita responsabilidade para com o excluído, uma vez que a sociedade, por intermédio de todos, é corresponsável nesse processo de cumprimento democrático. 


\section{Referências bibliográficas}

ADOÇÃO: deputados apontam necessidade de mudança cultural. Agência Câmara de Notícias. Brasília-DF, 28 maio 2008. Disponível em: <http://www2.camara.gov.br/agencia/noticias.htm>. Acesso em: 24 out. 2010.

ALEXY, Robert. Teoria de los derechos fundamentales. Madrid: Centro de Estudios Constitucionales, 1999.

ALMEIDA, Alberto Carlos. A cabeça do brasileiro. Rio de Janeiro:

Record, 2007.

ATCHABAHIAN, Serge. Princípio da igualdade e ações afirmativas. São Paulo: SRS Editora, 2006.

BANCO de dados nacional facilita adoção. Jornal do Senado, Especial Cidadania. v. 7, n. 269, 20 jul./26 jul. 2009. Disponível em: < http:// www2.senado.gov.br/bdsf/bitstream/id/159845/1/090720_269.pdf>.

BARROSO, Luis Roberto. Interpretação e aplicação da Constituição. São Paulo: Saraiva, 2002.

BRASIL. Projeto de Lei no 6.264, de 25 de novembro de 2005. Institui o Estatuto da Igualdade Racial. Disponível em: < http://www.camara.gov. br/proposicoesWeb/fichadetramitacao?idProposicao $=307731>$.

BRASIL. Lei $n^{\circ} 10.741$, de $1^{\circ}$ de outubro de 2003. Dispõe sobre o Estatuto do Idoso e dá outras providências. Disponível em: < http:// www010.dataprev.gov.br/sislex/paginas/42/2003/10741.htm>.

. Lei no 10.639, de 9 de janeiro de 2003. Altera a Lei nº 9.394, de 20 de dezembro de 1996, que estabelece as diretrizes e bases da educação nacional, para incluir no currículo oficial da Rede de Ensino a obrigatoriedade da temática "História e Cultura Afro-Brasileira", e dá outras providências. Disponível em: < http://www.planalto.gov.br/ ccivil_03/leis/2003/L10.639.htm>.

Lei $n^{\circ}$ 11.340, de 7 de agosto de 2006 (Lei Maria Penha).

Cria mecanismos para coibir a violência doméstica e familiar contra a mulher. Disponível em: <http://www.normaslegais.com.br/legislacao/ lei11340.htm>.

Constituição da República Federativa do Brasil, de 5 de outubro de 1988. A Lei reservará percentual dos cargos e empregos públicos para as pessoas portadoras de deficiência e definirá os critérios de sua 
admissão. Disponível em: <http://www.senado.gov.br/legislacao/const/ con1988/CON198805.10.1988/CON1988.pdf>.

COMPARATO, Fábio Konder. Ética: direito, moral e religião no mundo moderno. São Paulo: Companhia das Letras, 2006.

DERRIDA, Jacques. Força de lei: o fundamento místico da autoridade. Trad. Leyla Perrone-Moisés. São Paulo: WMF Martins Fontes, 2007.

DUAILIBI, Julia; IWASSO, Simone. Maioria dos que querem adotar ganha até 5 mínimos. O Estado de S. Paulo, Vida \&, p. A17, 15 nov. 2008.

DUSSEL, Enrique. Ética da libertação: na idade da globalização e da exclusão. Petrópolis: Vozes, 2000.

FERNANDES, Florestan. O negro no mundo branco. São Paulo: Difel, 1989.

FREYRE, Gilberto. Casa grande \& senzala. Rio de Janeiro: Record, 2001.

GIACÓIA, Gilberto. Justiça e dignidade. Argumenta Revista Jurídica, Jacarezinho-PR, n. 2, p. 11-31, 2002.

GOMES, Joaquim Benedito Barbosa. O debate constitucional sobre as ações afirmativas. In: SANTOS, Renato Emerson dos; LOBATO, Fátima (Org.). Ações afirmativas: políticas públicas contra as desigualdades raciais. Rio de Janeiro: DP\&A, 2003.

HOLANDA, Sérgio Buarque de. Raízes do Brasil. 26. ed. São Paulo: Companhia das Letras, 1995.

KOZICKI, Katya. A interpretação do direito e a possibilidade de justiça em Jacques Derrida. In: FONSECA, Ricardo Marcelo (Org.). Crítica da modernidade: diálogos com o direito. v. 1. Florianópolis: Fundação Boiteux, 2005. p. 129-143.

A política na perspectiva da filosofia da diferença. In:

OLIVEIRA, Manfredo et al.(Org.). Filosofia política contemporânea. v. 1. Petrópolis: Vozes, 2003. p. 141-160.

Democracia radical e cidadania: repensando a igualdade e a diferença a partir do pensamento de Chantal Mouffe. In: FONSECA, Ricardo Marcelo (Org.). Repensando a Teoria do Estado. v. 1. Belo Horizonte: Fórum, 2004. p. 327-346.

LACLAU, Ernesto. Emancipation(s). London: Verso, 2007. 
MELLO, Celso Antonio Bandeira de. Conteúdo jurídico do princípio da igualdade. 3. ed. São Paulo: Malheiros, 1993.

MOUFFE, Chantal. O regresso do político. Lisboa: Gradiva, 1996.

. Teoria política, direitos e democracia. Trad. Katya Kozicki. In: FONSECA, Ricardo Marcelo (Org.). Repensando a Teoria do Estado. Belo Horizonte: Fórum, 2004. p. 379-392.

REALE, Miguel. Lições preliminares do direito. São Paulo: Saraiva, 1973.

RISÉRIO, Antonio. A utopia brasileira e os movimentos negros. São Paulo: 34 Letras, 2007.

ROCHA, Cármen Lúcia Antunes. Ação afirmativa: o conteúdo democrático do princípio da igualdade jurídica. Revista de Informação Legislativa, São Paulo, n. 15, p. 85-99, 1996.

WALZER, Michael. Esferas da justiça: uma defesa do pluralismo e da igualdade. Trad. de Jussara Simões. São Paulo: Martins Fontes, 2003.

YOSHINO, Kenji. Covering: the hidden assault on our civil rights. New York: Random House Paperback, 2006.

Luis Otávio Vincenzi Agostinho, mestrando em Ciências Jurídicas na Universidade Estadual do Norte do Paraná (Uenp), é professor de Direito Ambiental e Agrário nessa Universidade.

luisotavio_agostinho@yahoo.com.br

Vladimir Brega Filho, doutor em Direito pela Pontifícia Universidade Católica de São Paulo (PUC-SP), é professor titular do Programa de Mestrado em Ciência Jurídica da Universidade Estadual do Norte do Paraná (Uenp).

bregafilho@uol.com.br

Recebido em 21 de março de 2011.

Aprovado em 29 de setembro de 2011. 